\title{
Comparative Liquid Chromatographic Study for Concurrent Determination of Canagliflozin and Metformin in Combined Tablets
}

\author{
Wafaa A. Zaghary, ${ }^{1}$ Shereen Mowaka, ${ }^{2,3,4}$ and Moataz S. Hendy ${ }^{2,4}$ \\ ${ }^{1}$ Pharmaceutical Chemistry Department, Faculty of Pharmacy, Helwan University, Ein Helwan, Cairo 11795, Egypt \\ ${ }^{2}$ Pharmaceutical Chemistry Department, Faculty of Pharmacy, The British University in Egypt, El-Sherouk City, Cairo 11837, Egypt \\ ${ }^{3}$ Analytical Chemistry Department, Faculty of Pharmacy, Helwan University, Ein Helwan, Cairo 11795, Egypt \\ ${ }^{4}$ The Center for Drug Research and Development (CDRD), Faculty of Pharmacy, The British University in Egypt, \\ El-Sherouk City, Cairo 11837, Egypt
}

Correspondence should be addressed to Moataz S. Hendy; Moataz.Sobhy@bue.edu.eg

Received 8 August 2017; Revised 8 October 2017; Accepted 16 October 2017; Published 3 December 2017

Academic Editor: Josep Esteve-Romero

Copyright (C) 2017 Wafaa A. Zaghary et al. This is an open access article distributed under the Creative Commons Attribution License, which permits unrestricted use, distribution, and reproduction in any medium, provided the original work is properly cited.

New HPLC-UV method (method A), for simultaneous determination of metformin (MET) and canagliflozin (CANA), was developed and compared to another novel UPLC-UV method (method B) in their tablet combination. Concerning method A, isocratic separation was done by C18 column $(100 \mathrm{~mm} \times 2.1 \mathrm{~mm}, 3 \mu \mathrm{m})$ using methanol and $0.03 \mathrm{M}$ phosphate buffer (75:25, $v / v)$ at $\mathrm{pH} 3.2$ as a mobile phase. Meanwhile, chromatographic separation in method B was achieved via Hypersil ${ }^{\circledR}$ gold $(50 \mathrm{~mm}$ $\times 2.1 \mathrm{~mm}, 1.9 \mu \mathrm{m})$. Mobile phase was methanol and $0.03 \mathrm{M}$ phosphate buffer at ratio of $80: 20 \mathrm{v} / \mathrm{v}$. In both, detection was done at wavelength of $240 \mathrm{~nm}$. Method A showed satisfactory linearity results over $1-50 \mu \mathrm{g} \cdot \mathrm{mL}^{-1}$ and $0.5-100 \mu \mathrm{g} \cdot \mathrm{mL}^{-1}$, while $\mathrm{method} \mathrm{B}$ linearity was at $0.1-50 \mu \mathrm{g} \cdot \mathrm{mL}^{-1}$ and $0.25-100 \mu \mathrm{g} \cdot \mathrm{mL}^{-1}$ for CANA and MET, respectively. In terms of accuracy and precision, method A accuracy was $99.81 \pm 0.73$ and $99.37 \pm 0.54$, while method B gave accuracy of $99.47 \pm 1.03$ and $99.73 \pm 0.89$ for CANA and MET, respectively. For precision, the $\%$ RSD was found to be less than $2 \%$ for three concentrations analyzed three times. The two methods are convenient for quality laboratories, yet the UPLC method offered the advantage of shorter run times and higher sensitivity.

\section{Introduction}

Diabetes mellitus type 2 (DMT2) is a progressive disease, and to fully control hyperglycemia after initial monotherapy and lifestyle modification, combination treatments are usually needed to maintain glycemic control [1].

Metformin hydrochloride (MET) (Figure 1(b)) is the most widely used drug for the treatment of DMT2 with a dimethylbiguanidine structure. Metformin-based combinations are found to be better in efficacy and tolerance rather than other single hypoglycemic agent therapy. The therapeutic properties of metformin are due to its action in suppressing glucose production by liver, especially gluconeogenesis. Also metformin increases the insulin sensitivity in peripheral tissue $[2,3]$.
Canagliflozin (CANA), the other agent in this binary study (Figure 1(a)), is sodium glucose cotransporter 2 (SGLT2) inhibitor, which was developed for DMT2 treatment by Janssen Pharmaceuticals Inc. 2014. Canagliflozin improves urinary glucose excretion via decreasing the glucose renal threshold. SGLT2 is glucose transporter with low affinity and high capacity which is the main cause for renal reabsorption of glucose [4].

Because CANA is a relatively new drug, there are no official methods for its analysis in pharmacopeias but MET has authentic techniques of analysis in the British Pharmacopeia (BP) [5] and United State Pharmacopeia (USP) [6]. Referring to the literature, sparse methods were proclaimed [7-9] for concentration assurance of CANA and MET simultaneously in pharmaceutical preparations or in laboratory prepared 


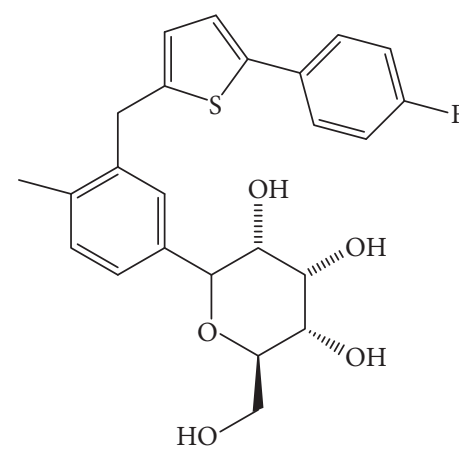

(a)

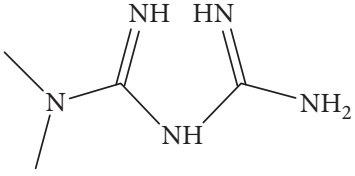

(b)

FIGURE 1: Structures of canagliflozin (a) and metformin (b).

TABLE 1: Comparison between different LC-UV reported methods and the proposed methods for simultaneous determination of CANA and MET.

\begin{tabular}{|c|c|c|c|c|}
\hline Methods & Column & Mobile phase & $\begin{array}{l}\text { Run time } \\
\text { (min) }\end{array}$ & Sensitivity \\
\hline Reported method [7] & $\begin{array}{l}\mathrm{C}_{18} \text { column } \\
(250 \mathrm{~mm} \times 4.6 \mathrm{~mm}, 5 \mu \mathrm{m}) \\
\text { At ambient temperature }\end{array}$ & $\begin{array}{l}\text { Ammonium acetate : acetonitrile } \\
\quad(\mathrm{pH} 3.5)(65: 35, v / v)\end{array}$ & $8 \min$ & $\begin{array}{l}\text { CANA }\left(5-30 \mu \mathrm{g} \cdot \mathrm{mL}^{-1}\right) \\
\operatorname{MET}\left(50-300 \mu \mathrm{g} \cdot \mathrm{mL}^{-1}\right)\end{array}$ \\
\hline Reported method [8] & $\begin{array}{l}\mathrm{C}_{18} \text { column } \\
(250 \mathrm{~mm} \times 4.6 \mathrm{~mm}, 5 \mu \mathrm{m}) \\
\text { At Temperature at } 30^{\circ} \mathrm{C}\end{array}$ & $\begin{array}{l}\text { Phosphate buffer: acetonitrile } \\
\quad(\mathrm{pH} 4.5)(65: 35, v / v)\end{array}$ & $4 \mathrm{~min}$ & $\begin{array}{l}\text { CANA }\left(5-30 \mu \mathrm{g} \cdot \mathrm{mL}^{-1}\right) \\
\operatorname{MET}\left(50-300 \mu \mathrm{g} \cdot \mathrm{mL}^{-1}\right)\end{array}$ \\
\hline Reported method [9] & $\begin{array}{l}\text { ODS column } \\
(250 \mathrm{~mm} \times 4.6 \mathrm{~mm}, 5 \mu \mathrm{m}) \\
\text { At Temperature at } 30^{\circ} \mathrm{C}\end{array}$ & $\begin{array}{l}\text { Phosphate buffer: acetonitrile : methanol } \\
\qquad(\mathrm{pH} 4.5)(40: 40: 20, v / v)\end{array}$ & $7 \mathrm{~min}$ & $\begin{array}{l}\text { CANA }\left(5-30 \mu \mathrm{g} \cdot \mathrm{mL}^{-1}\right) \\
\operatorname{MET}\left(50-300 \mu \mathrm{g} \cdot \mathrm{mL}^{-1}\right)\end{array}$ \\
\hline Proposed method (A) & $\begin{array}{l}\mathrm{C}_{18} \text { column } \\
(100 \mathrm{~mm} \times 2.1 \mathrm{~mm}, 3 \mu \mathrm{m}) \\
\text { At ambient temperature }\end{array}$ & $\begin{array}{l}\text { Methanol : phosphate buffer } \\
\quad(\mathrm{pH} 3.2)(75: 25, v / v)\end{array}$ & $1.1 \mathrm{~min}$ & $\begin{array}{l}\text { CANA }\left(1-50 \mu \mathrm{g} \cdot \mathrm{mL}^{-1}\right) \\
\operatorname{MET}\left(0.5-100 \mu \mathrm{g} \cdot \mathrm{mL}^{-1}\right)\end{array}$ \\
\hline Proposed method (B) & $\begin{array}{l}\text { Hypersil gold } \\
(50 \mathrm{~mm} \times 2.1 \mathrm{~mm}, 1.9 \mu \mathrm{m}) \\
\text { At ambient temperature }\end{array}$ & $\begin{array}{l}\text { Methanol : phosphate buffer } \\
\quad(\mathrm{pH} 3.5)(80: 20 \mathrm{v} / \mathrm{v})\end{array}$ & $1 \mathrm{~min}$ & $\begin{array}{l}\text { CANA }\left(0.1-50 \mu \mathrm{g} \cdot \mathrm{mL}^{-1}\right) \\
\operatorname{MET}\left(0.25-100 \mu \mathrm{g} \cdot \mathrm{mL}^{-1}\right)\end{array}$ \\
\hline
\end{tabular}

mixtures. An objective comparison between the reported and proposed methods was manifested in Table 1 to facilitate proper understanding of the aim of this study.

Other few methods were found for determination of CANA alone, either in dosage form or in plasma. Patel et al. [10] and Kaur et al. [11] achieved concentration determination of CANA in bulk and in its dosage form using UVspectroscopy. While Suneetha and Sharmila [12] achieved more sensitive method using reversed phase HPLC technique, Iqbal et al. $[13,14]$ have performed UHPLC method for detection of CANA in plasma using MS/MS and fluorescence detectors each in a separate study. Despite the low limit of detection and quantification achieved in this study, mass and fluorescence detectors are considered quiet expensive and less notorious. They may not be used as regular method in quality control laboratories.

On the contrary, various analysis methodologies were developed for investigation of MET using both spectrophotometry and chromatographic techniques. Metformin was determined via UV-spectrophotometry in presence of the recent empagliflozin in their dosage form [15] and of trending gliptins: alogliptin and linagliptin either in prepared mixtures or in marketed dosage forms $[16,17]$. In addition to that, there are remarked methods reported for analysis of MET utilizing either ultra or high performance liquid chromatography with other hypoglycemic agents such as empagliflozin [18], linagliptin, alogliptin, pioglitazone [19], sitagliptin [20, 21], and sitagliptin degradation product. Recently, the sensitive LC-MS technique with various bioanalytical applications was also found in literature for MET detection and quantification [22-27].

There is no UPLC-UV method found, for CANA and MET simultaneous quantification in tablets. Moreover, UPLC is proven to be more economic than HPLC with less organic solvent consumption and less run time and resulting in relatively more sharp peaks. Besides, UPLC offers higher sensitivity in nanogram level facilitating development of new bioanalytical methods for the studied drugs. 
This work aims to evolve new, yet more sensitive UPLCUV and HPLC-UV methods for concurrent quantification of MET and CANA in bulk and in their pharmaceutical preparation. This is followed by full validation for each method. The authors' idea for a comparative study using two different stationary phases has emerged from the need to find the most suitable analytical method in short time to be applicable in QC labs giving the analyst the choice of the preferable detector according to the underlying application. Furthermore, outputs from a comparative study using two columns with different dimensions will be useful for analysts working in the area of drug quality control.

\section{Experimental}

2.1. Instrumentation for Methods $A$ and $B$. The wielded liquid chromatography facility was a UPLC of Thermo Fisher with Ultimate 3000 Ultra Performance Liquid Chromatography (USA). UV Detector (DAD, $3000 \mathrm{RS}$ ) and (WPS-3000TRS, Thermo Scientific) (USA) autosampler were employed. For HPLC technique (method A) a BDS Hypersil (USA) C18 column $(100 \times 3 \mathrm{~mm}, 3 \mu \mathrm{m})$ was used and for UPLC technique (method B) Hypersil gold (USA) C18 column $(50 \mathrm{~mm}$ $\times 2.1 \mathrm{~mm}, 1.9 \mu \mathrm{m}$ ) was used. Software utilized for LC system was ChromLeon 7. Solvent degassing was utilized using Elmasonic S $60 \mathrm{H}$ water bath sonicator (Germany). To adjust $\mathrm{pH}$, Jenway digital $\mathrm{pH}$ meter (UK) was employed.

2.2. Source of Samples and Reagents. Industrial grade row material of CANA and MET and Invokamet ${ }^{\circledR}$ tablets that contain in each tablet $50 \mathrm{mg}$ CANA and $1000 \mathrm{mg}$ MET were obtained by Janssen Pharmaceuticals, Inc. Co. (USA). Metformin (MET) was kindly supplied by "Chemical Industries Development” (CID) Cairo, Egypt; canagliflozin (CANA) was purchased from Baoji Guokang Bio-Technology Co., Ltd., China. CANA and MET bulk purity were found to be $99.90 \%$ and $99.88 \%$, respectively. Deionized water was produced in-house, and acetonitrile, methanol, and potassium phosphate monobasic powder of HPLC grade were purchased from Sigma Aldrich.

\subsection{Chromatography Separation Conditions}

2.3.1. High Performance LC Separation (Method A). Chromatographic method was applied via Hypersil BDS C18 column $(100 \times 3 \mathrm{~mm}, 3 \mu \mathrm{m})$ from Thermo Scientific, New York, USA. A binary mobile phase consisting of $75 \%$ methanol and $25 \%(0.03 \mathrm{M})$ phosphate buffer $\mathrm{pH}$ maintained at 3.2 adjusted by phosphoric acid was used. Prior to mobile phase usage, it was Millipore-filtered through 0.2 Millipore filter by vacuum Buchner and then degassed. The separation was done at $240 \mathrm{~nm}$. Mobile phase was pumped in $1.3 \mathrm{mLmin}^{-1}$ flow rate, where isocratic elution was done at room temperature. $10 \mu \mathrm{L}$ was adapted as sufficient injection volume.

2.3.2. Ultra Performance LC (Method B). Separation was carried out by a Hypersil gold column (column packed with ultrapure silica), $50 \times 2.1 \mathrm{~mm}(1.9 \mu \mathrm{m})$. Isocratic elution was utilized, and mobile phase was prepared as a mixture of methanol and 0.03 phosphate buffer $(80: 20, \mathrm{v} / \mathrm{v})$. pH was adjusted at 3.5 using phosphoric acid. $240 \mathrm{~nm}$ wavelength was selected. Mobile phase was filtered initially using $0.2 \mu \mathrm{m}$ membrane filter and then degassed before its use. Flow rate of $0.4 \mathrm{mLmin}^{-1}$ was adapted. Separation was done at room temperature with $10 \mu \mathrm{L}$ injection volume.

2.4. Stock Preparations. CANA and MET stock solutions of concentration $1 \mathrm{mg} \cdot \mathrm{mL}^{-1}$ were initially accurately prepared with methanol. By diluting the corresponding stock solutions with mobile phases, we obtain the working solutions that were used in each method (A and B). All of them were conserved at $4^{\circ} \mathrm{C}$ and junked after 30 days.

2.5. Preparation of Tablet Samples. Ten tablets of Invokamet 50 CANA/1000 MET were solely weighed, powdered, and blended. Specific quantity of the obtained powder contains $100 \mathrm{mg}$ of MET and $5 \mathrm{mg}$ of CANA was dissolved in $30 \mathrm{~mL}$ of methanol in a $100 \mathrm{~mL}$ volumetric flask, sonicated for $20 \mathrm{~min}$. The solution was filtered and made up to the final volume with methanol. Then certain dilutions were done to prepare the investigated concentrations of the two components via mobile phase. This step was accompanied with addition of precise calculated amount of pure drug to achieve standard addition technique.

\subsection{Applied Procedures}

2.6.1. HPLC Method Calibration Curve. Calibration curves were built up via preparing five solutions of each drug using the mentioned mobile phase within ranges of concentration: $1-50 \mu \mathrm{g} \cdot \mathrm{mL}^{-1}$ and $0.5-100 \mu \mathrm{g} \cdot \mathrm{mL}^{-1}$ for CANA and MET, respectively. $10 \mu \mathrm{L}$ aliquots were injected onto the stationary phase. Calibration curves were then built up for each drug by plotting the peak area of each drug absorbance against its corresponding concentrations.

2.6.2. UPLC Method Calibration Curve. Calibration curves were built up by preparing five solutions of each drug using the mobile phase in ranges of concentration of $0.1-50 \mu \mathrm{g} \cdot \mathrm{mL}^{-1}$ and $0.25-100 \mu \mathrm{g} \cdot \mathrm{mL}^{-1}$ for CANA and MET, respectively, and then only $10 \mu \mathrm{L}$ was injected. By plotting area under the peak (AUP) of the corresponding drug against its concentration, the calibration curve was attained.

2.6.3. Study of CANA and MET in Laboratory Mixtures and Invokamet Tablets. The procedures declared earlier were applied for different ratios of CANA and MET and for tablet samples, prepared under Section 2.5. Different concentrations of the investigated drugs were obtained from each computed equation of regression.

\section{Results and Discussion}

It is worth mentioning that the proposed methods are the first methods applying UPLC techniques for the analysis of the studied drugs rather than HPLC technique. UPLC is more advantageous [28] in terms of withstanding the high system back pressure, improved resolution, shorter run 


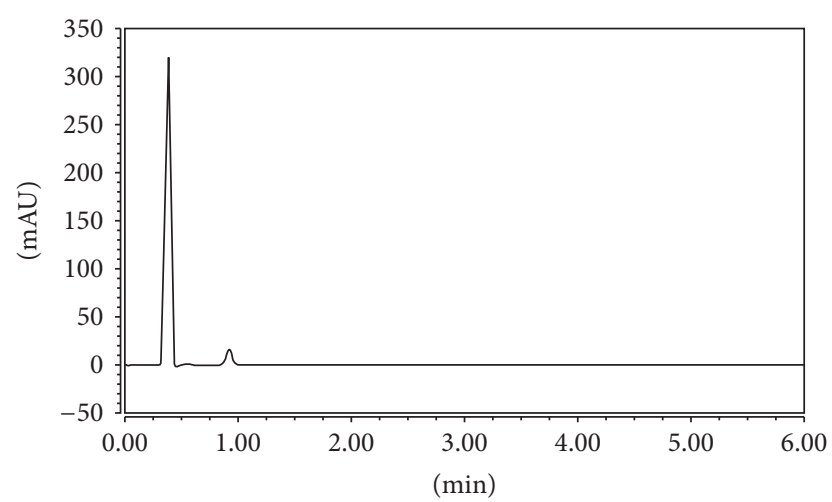

(a)

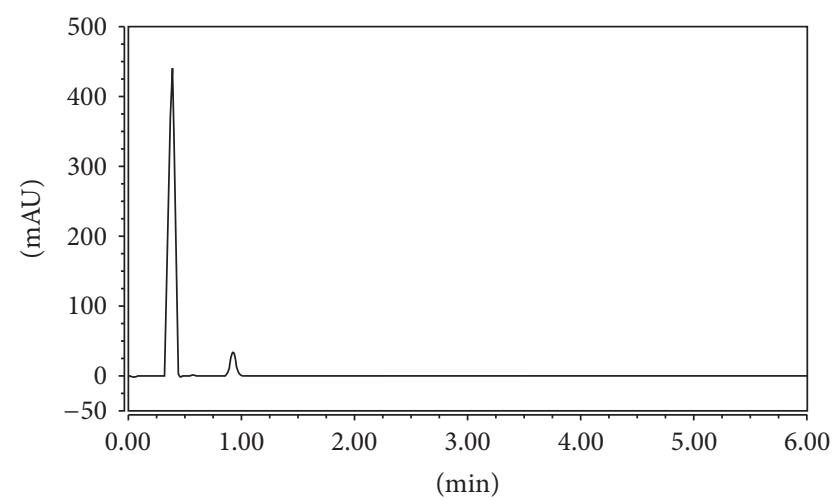

(b)

FIgURE 2: (a) HPLC chromatogram of laboratory mixture containing $50 \mu \mathrm{g} \cdot \mathrm{mL}^{-1}$ of MET at $0.4 \mathrm{~min}$ and $25 \mu \mathrm{g} \cdot \mathrm{mL}^{-1}$ of CANA at $0.9 \mathrm{~min}$. (b) UPLC chromatogram of a laboratory mixture containing $50 \mu \mathrm{g} \cdot \mathrm{mL}^{-1}$ of MET at $0.4 \mathrm{~min}$ and $25 \mu \mathrm{g} \cdot \mathrm{mL}^{-1}$ of CANA at $0.9 \mathrm{~min}$.

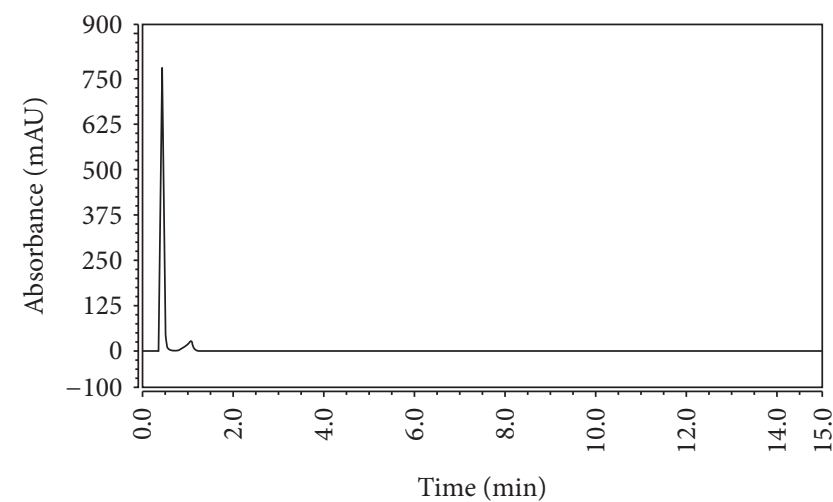

(a)

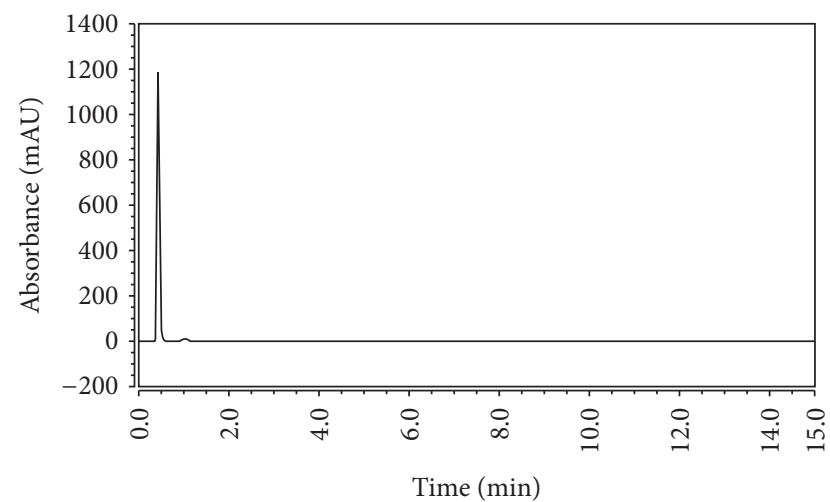

(b)

Figure 3: (a) HPLC chromatogram of Invokamet tablet extract containing $60 \mu \mathrm{gmL}^{-1}$ of MET at $0.4 \mathrm{~min}$ and $3 \mu \mathrm{gmL}^{-1}$ of CANA at $0.9 \mathrm{~min}$ (b) UPLC chromatogram of Invokamet tablet extract containing $60 \mu \mathrm{gmL}^{-1}$ of MET at $0.4 \mathrm{~min}$ and $3 \mu \mathrm{gmL}^{-1}$ of CANA at $0.9 \mathrm{~min}$.

times, and fewer consumables. Also the proposed methods were developed with simple mobile phase which enables their further application on different detectors. The obtained results confirmed the validity of the methods showing better resolution and sharp peaks.

Using a Hypersil gold C18 column $(50 \times 2.1 \mathrm{~mm}, 1.9 \mu \mathrm{m})$ showed better results than the commonly used Symmetry ${ }^{\circledR}$ C18 column $(100 \times 2.1 \mathrm{~mm}, 3 \mu \mathrm{m})$. When high pressure applied in UPLC was combined with $1.9 \mu \mathrm{m}$ particles, high peak capacity was observed which is crucial for sensitive CANA determination due to its low contribution in the pharmaceutical combination with MET.

\subsection{Chromatographic Investigations concerning Separation} Conditions. Concerning method A, HPLC analysis of the drugs was firstly tried using various combinations of either methanol or acetonitrile with water, yet no separation occurred. Addition of buffer was then decided. Phosphate buffer was chosen with two concentrations $(0.03$ and $0.05 \mathrm{M})$ with varying ratios with the organic phase. All reported methods showed separation using acetonitrile. So it was implemented first with diverse ratios (from $40 \%$ to $75 \%$ ) of the total mobile phase. Separation was done using acetonitrile and phosphate buffer; methanol then was tried to separate the mixture owing to its lower cost relatively to acetonitrile. The ratio of $75: 25$ methanol:0.03 M phosphate buffer $v / v$ ( $\mathrm{pH}: 3.2)$ gave the best peak resolution with valid, satisfactory, and rational determination values as revealed in Figures 2 and 3. Mobile phase was pumped on HPLC BDS Hypersil C18 column $(100 \times 3 \mathrm{~mm}, 3 \mu \mathrm{m})$. Flow rate was optimized to give each peak a smart outline with optimum retention time; it was adjusted to be $1.3 \mathrm{~mL} \cdot \mathrm{min}^{-1}$. Separation was done at wavelength of $240 \mathrm{~nm}$ with no applied temperature on column.

Targeting the optimum detection of the studied drugs, method B was applied using an UPLC Hypersil gold column $(50 \times 3 \mathrm{~mm}, 1.9 \mu \mathrm{m})$. Mobile phase of methanol or acetonitrile with water results in no separation. Phosphate buffer $(0.03 \mathrm{M})$ 
TABLE 2: Results obtained by the HPLC-UV and UPLC-UV methods for the simultaneous determination of CANA and MET in their binary mixture.

\begin{tabular}{|c|c|c|c|c|}
\hline \multirow{2}{*}{ Parameters } & \multicolumn{2}{|c|}{ HPLC } & \multicolumn{2}{|c|}{ UPLC } \\
\hline & CANA & MET & CANA & MET \\
\hline Linearity range $\left(\mu \mathrm{g} \cdot \mathrm{mL}^{-1}\right)$ & $1-50$ & $0.5-90$ & $0.1-50$ & $0.25-100$ \\
\hline Slope & 0.9102 & 0.9319 & 0.8821 & 1.0795 \\
\hline Intercept & 0.3367 & 0.255 & 0.1499 & 0.5372 \\
\hline Correlation coefficient & 0.9999 & 0.9999 & 0.9999 & 0.9999 \\
\hline Accuracy $($ mean $\pm S D)$ & $99.81 \pm 0.73$ & $99.37 \pm 0.54$ & $99.47 \pm 1.034$ & $99.73 \pm 0.89$ \\
\hline LOD & 0.7154 & 0.9327 & 0.463 & 0.614 \\
\hline LOQ & 2.1075 & 2.8263 & 1.406 & 1.862 \\
\hline Precision (\% RSD) Repeatability & 1.31 & 1.47 & 0.48 & 0.71 \\
\hline Interday precision (reproducibility) & 1.75 & 0.90 & 0.89 & 1.85 \\
\hline Specificity $($ mean \pm SD) & $99.60 \pm 0.33$ & $100.38 \pm 1.20$ & $99.89 \pm 1.39$ & $99.09 \pm 1.31$ \\
\hline
\end{tabular}

was tried in increasing ratios till $20 \%$ of the total mobile phase with methanol pumped into the stationary phase implementing isocratic mode; this achieves separation with smart peak shapes. Certainly, optimization of the mobile phase $\mathrm{pH}$ was a must. It was expected to be in the acidic region (2.5 and 3.5) to ensure its value below the pka of the studied drugs by more than two units; therefore adjusting $\mathrm{pH}$ to 3.5 using phosphoric acid showed the best results. Wavelength of detection was also $240 \mathrm{~nm}$ for achieving highest sensitivity for two drugs. In addition, the methanol percent was essential for this technique to improve the resolution between the two eluted peaks obtained with improved shape and smooth outline in room temperature. $0.4 \mathrm{~mL} \cdot \mathrm{min}^{-1}$ was the flow rate and injection volume was $10 \mu \mathrm{L}$.

3.2. Validation of the Methods. Validation was done in accordance with ICH guidelines [29].

3.2.1. Linearity. Under the optimum conditions, CANA and MET were evaluated by studying certain different concentrations of each drug. Satisfactory linearity was attained between area under the curve (AUC) and its corresponding concentration of each drug; equations of regression were obtained with high value of correlation coefficient as listed in Table 2. Method A showed satisfactory linearity within concentration ranges of $1-50 \mu \mathrm{g} \cdot \mathrm{mL}^{-1}$ and $0.5-100 \mu \mathrm{g} \cdot \mathrm{mL}^{-1}$ for CANA and MET, respectively, while method $\mathrm{B}$ showed good results using ranges of $0.1-50 \mu \mathrm{g} \cdot \mathrm{mL}^{-1}$ and $0.25-100 \mu \mathrm{g} \cdot \mathrm{mL}^{-1}$ for CANA and MET, respectively.

3.2.2. Accuracy and Precision. Results' accuracy was verified through calculation of percentage recovery of five concentrations of each drug by each method (A and B). Besides, calculation of percentage recovery of each drug in laboratory prepared mixture was carried out. The findings include standard deviations and the mean of the recovery is mentioned in Table 2. Precision was verified by analyzing three concentrations of both CANA and MET by each method three times, within the same day to test intraday repeatability. Then to test interday precision and to confirm reproducibility, analysis of three diverse concentrations of the analytes was done on three successive days using the procedures declared earlier. The resultant \% RSD was found to be less than $2 \%$ in the three concentrations, as found in Table 2.

3.2.3. Robustness. Robustness of methods A and B was verified by the peak area uniformity of the analytes after intentional minor changes performed in chromatographic conditions. This was ascertained by studying the effect of minor changes in experimental parameters on the resolution between the two peaks of MET and CANA. For the HPLC method using the 3 -micron $\mathrm{C} 18$ column, flow rate was altered from $1.3 \mathrm{mLmin}^{-1}$ to $1.2 \mathrm{mLmin}^{-1}$ and $1.4 \mathrm{mLmin}^{-1}$, the ratio of the organic solvent was altered by $\% \pm 1$, and the value of $\mathrm{pH}$ of the mobile phase was changed from 3.2 to 2.9 and 3.1; there was no significant change in the results, indicating good robustness of those methods.

3.2.4. Specificity. In the present work, specificity was tested by analyzing four diverse concentrations of each drug using methods A and B in the presence of other drugs as in laboratory prepared mixtures (Table 3) and in presence of additives and excipients of the combination dosage form as represented in Table 4.

3.2.5. Limit of Detection and Limit of Quantification for the Proposed Methods. Limit of detection (LOD) and limit of quantification (LOQ) were computed and represented in Table 2. LOD is the concentration of any analyte at signal/noise ratio of 3.3 ; meanwhile LOQ is at signal/noise ratio of 10 .

3.2.6. System Suitability Tests. Those tests were done to ensure that the chromatographic method is sufficiently reproducible, which mainly include column efficiency, tailing factor of chromatographic peaks, and resolution between peaks. All these results are found in Table 5. 
TABLE 3: Determination of CANA and MET in lab prepared mixtures by the proposed methods.

\begin{tabular}{|c|c|c|c|c|c|c|}
\hline \multirow{2}{*}{ Mix. number } & \multirow{2}{*}{$\begin{array}{r}\text { CANA } \\
\text { Take }\end{array}$} & \multirow{2}{*}{$\begin{array}{l}\text { MET } \\
\text { L) }\end{array}$} & \multicolumn{2}{|c|}{ CANA } & \multicolumn{2}{|c|}{ MET } \\
\hline & & & Found $(\mu \mathrm{g} / \mathrm{mL})$ & $\%$ recovery & Found $(\mu \mathrm{g} / \mathrm{mL})$ & $\%$ recovery \\
\hline \multicolumn{7}{|c|}{ HPLC method } \\
\hline 1 & 8 & 70 & 8.03 & 100.45 & 69.74 & 99.63 \\
\hline 2 & 10 & 65 & 10.16 & 101.75 & 64.38 & 99.05 \\
\hline 3 & 20 & 80 & 19.81 & 98.99 & 79.51 & 99.39 \\
\hline 4 & 25 & 65 & 24.88 & 99.53 & 65.27 & 100.42 \\
\hline $5^{*}$ & 3 & 60 & 2.94 & 98.09 & 59.71 & 99.51 \\
\hline & \multicolumn{2}{|c|}{$M e a n \pm S D$} & \multicolumn{2}{|c|}{$99.76 \pm 1.40$} & \multicolumn{2}{|c|}{$99.60 \pm 0.51$} \\
\hline \multicolumn{7}{|c|}{ UPLC method } \\
\hline 1 & 8 & 70 & 7.94 & 99.21 & 70.20 & 100.29 \\
\hline 2 & 10 & 65 & 9.92 & 99.17 & 65.58 & 100.89 \\
\hline 3 & 20 & 80 & 19.85 & 99.23 & 78.64 & 98.29 \\
\hline 4 & 25 & 65 & 24.75 & 99.01 & 65.42 & 100.64 \\
\hline \multirow[t]{2}{*}{$5^{*}$} & 3 & 60 & 3.01 & 100.19 & 59.69 & 99.48 \\
\hline & \multicolumn{2}{|c|}{ Mean $\pm S D$} & \multicolumn{2}{|c|}{$99.36 \pm 0.47$} & \multicolumn{2}{|c|}{$99.92 \pm 1.05$} \\
\hline
\end{tabular}

${ }^{*}$ Laboratory mixture represents the CANA: MET ratio as $1: 20$ as in dosage form.

3.2.7. Standard Addition Technique Application on Dosage Forms. This chromatographic methods were satisfyingly utilized for analysis of a pharmaceutical dosage form (Figure 2). Moreover, standard addition technique was employed. This technique is done by adding different known amounts of the pure drug to different known concentrations previously prepared, of the drug product using the procedure mentioned above. The final concentrations were then estimated using each corresponding equation of regression; the date is represented in Table 4.

3.3. Statistical Analysis. The obtained results for analysis of CANA and MET by those investigated UPLC and HPLC methods were statistically compared to the reported methods for CANA [7] and MET [27]. The values of computed $t$ and $F$ were lower than their tabulated values at $95 \%$ confidence level. This uncovers that there was no momentous difference concerning precision and accuracy as presented in Table 6.

3.4. Remarks about the Procedure. The lack of UPLC-UV methods for concurrent analysis of CANA and MET in tablets has motivated us to propose and develop such a method (method B). Based on our planned future work, this comparative study is considered a crucial step to decide which method can be further employed for the analysis and quantification of the drugs studied, with their different degradation products or in biological fluids. Furthermore, as in Table 1, the proposed HPLC method (method A) has many advantages over the previously reported HPLCUV methods including the usage of a simpler mobile phase with lowest buffer content, shorter run time, studying the validation parameters, and taking in consideration the ratio of two components in their pharmaceutical preparation.

Moreover, the developed UPLC technique (method B) has other major outcomes that include detection at most sensitive wavelength for the two studied drugs after preliminary investigation, using simple mobile phase which is a mixture containing higher ratio of organic phase with lowest concentration of phosphate buffer $(0.03 \mathrm{M})$, better resolution between peaks, adjusted $\mathrm{pH}$ less than the pka of the considered drugs by more than two units, lower LOD and LOQ values, and high throughput analysis, not to mention the sensitivity of the method which was able to detect CANA and MET in a concentration range between $100 \mathrm{ng} \cdot \mathrm{mL}^{-1}$ and $50000 \mathrm{ng} \cdot \mathrm{mL}^{-1}$ and $250 \mathrm{ng} \cdot \mathrm{mL}^{-1}$ and $100000 \mathrm{ng} \cdot \mathrm{mL}^{-1}$, respectively.

\section{Conclusion}

The proposed comparative chromatographic study has revealed that UPLC-UV (method B) is more sensitive. Moreover, not only does it offer more advantages, elegant complete separation, but also, compared to the HPLC-UV method, it offers shorter time of development and efficient analysis. Linearity at nanogram range using method B has supported our future plans for the analysis of the same drugs in the presence of their degradation products and in biological fluids. Furthermore, any of the proposed methods is suitable to be used conveniently in quality control laboratories.

\section{Conflicts of Interest}

The authors declare that they have no conflicts of interest. 


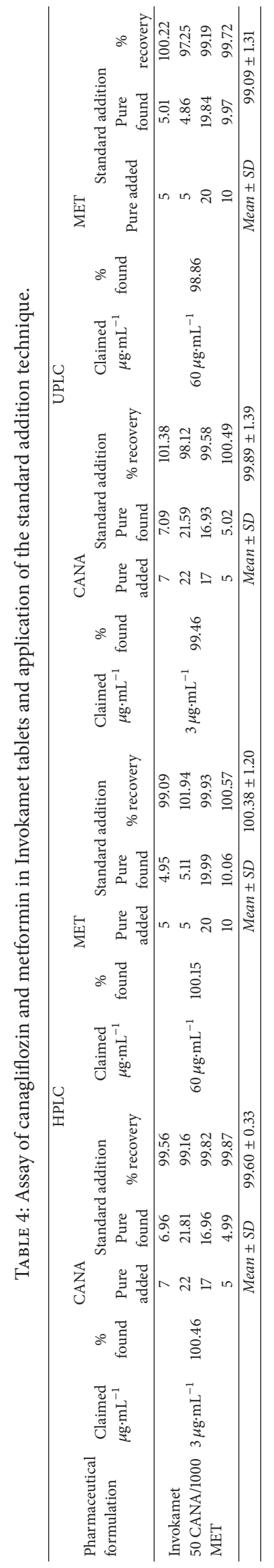


TABLE 5: System suitability tests for LC/UV methods for simultaneous determination of CANA and MET.

\begin{tabular}{|c|c|c|c|c|}
\hline \multirow{2}{*}{ Parameters } & \multicolumn{2}{|c|}{ HPLC } & \multicolumn{2}{|c|}{ UPLC } \\
\hline & CANA & MET & CANA & MET \\
\hline Retention time $\left(t_{R}\right)$ & 0.9 & 0.5 & 1 & 0.5 \\
\hline Resolution (Rs) & \multicolumn{2}{|c|}{2.8} & \multicolumn{2}{|c|}{2.5} \\
\hline Selectivity factor $(\alpha)$ & \multicolumn{2}{|c|}{0.5} & \multicolumn{2}{|c|}{0.5} \\
\hline Capacity factor $\left(K^{\prime}\right)$ & 14 & 7 & 13 & 8 \\
\hline Number of theoretical plates $(N)$ & 1296 & 400 & 1600 & 400 \\
\hline
\end{tabular}

TABLE 6: Statistical comparison between the results of the proposed methods and the reference methods for CANA [7] and MET [27].

\begin{tabular}{|c|c|c|c|c|c|c|}
\hline \multirow{3}{*}{ Values } & \multicolumn{4}{|c|}{ Proposed methods } & \multicolumn{2}{|c|}{ Reported methods } \\
\hline & \multicolumn{2}{|c|}{ HPLC } & \multicolumn{2}{|c|}{ UPLC } & \multirow{2}{*}{ CANA } & \multirow{2}{*}{ MET } \\
\hline & CANA & MET & CANA & MET & & \\
\hline Mean & 99.81 & 99.37 & 99.47 & 99.73 & 99.52 & 100.59 \\
\hline SD & 0.73 & 0.54 & 1.034 & 0.89 & 0.76 & 0.81 \\
\hline$\%$ RSD & 0.73 & 0.54 & 1.039 & 0.89 & 0.76 & 0.81 \\
\hline$n$ & 5 & 5 & 5 & 5 & 5 & 6 \\
\hline Variance & 0.53 & 0.29 & 1.07 & 0.79 & 0.58 & 0.66 \\
\hline Student's $t$-test ${ }^{\mathrm{b}}(2.571)$ & 0.6154 & 2.866 & 0.08712 & 1.678 & & \\
\hline$F$-value $^{\mathrm{b}}(6.388)$ & 1.084 & 2.250 & 1.851 & 1.207 & & \\
\hline
\end{tabular}

${ }^{\mathrm{b}}$ The values in the parenthesis are the corresponding theoretical values of $t$ and $F$ at $P=0.05$.

\section{References}

[1] S. E. Inzucchi, R. M. Bergenstal, J. B. Buse et al., "Management of hyperglycemia in type 2 diabetes: a patient-centered approach. Position statement of the American Diabetes Association (ADA) and the European Association for the Study of Diabetes," Diabetes Care, vol. 38, no. 1, pp. 140-149, 2012.

[2] C. J. Bailey and R. C. Turner, "Metformin," The New England Journal of Medicine, vol. 334, no. 9, pp. 574-579, 1996.

[3] D. Kirpichnikov, S. I. McFarlane, and J. R. Sowers, "Metformin: an update," Annals of Internal Medicine, vol. 137, no. 1, pp. 25-33, 2002.

[4] E. M. Wright, D. D. F. L. Loo, and B. A. Hirayama, "Biology of human sodium glucose transporters," Physiological Reviews, vol. 91, no. 2, pp. 733-794, 2011.

[5] The United States Pharmacopoeia 30, the National Formulary 25, Electronic version, US Pharmacopeial Convention, Rockville, MD, Maryland, 2007.

[6] “The British Pharmacopoeia," 2009, The Stationery Office: London; Electronic version; pp. 3813-3816.

[7] U. P. Panigrahy and A. S. K. Reddy, "A novel validated rphplc-dad method for the simultaneous estimation of metformin hydrochloride and canagliflozin in bulk and pharmaceutical tablet dosage form with forced degradation studies," Oriental Journal of Chemistry, vol. 31, no. 3, pp. 1489-1507, 2015.

[8] D. Gaware, R. Patil, and M. Harole, "A validated stability indicating RP-HPLC method for simultanious determination of metformin and canagliflozin in pharmaceutical formulation," World Journal of Pharmacy and Pharmaceutical Sciences, vol. 4, no. 12, pp. 631-640, 2015.

[9] N. Reddy and N. Chevela, "RP-HPLC Method development and validation for the simultaneous estimation of metformin and canagliflozin in tablet dosage form," International Journal of Pharma Sciences, vol. 5, no. 4, pp. 1155-1159, 2015.
[10] N. Patel, D. Shah, and D. Maheshwari, "Development and validation of UV- spectrophotometric estimation of canagliflozin in its pharmaceutical dosage form," International Journal of Pharmacy and Technology, vol. 7, no. 3, pp. 79779-79784, 2015.

[11] I. Kaur, S. Wakode, and H. Pal Singh, "Development and validation of UV spectroscopic method for determination of canagliflozin in bulk and pharmaceutical dosage form," Pharmaceutical Methods, vol. 6, no. 2, pp. 82-86, 2015.

[12] A. Suneetha and D. Sharmila, "A validated stability indicating RP-HPLC method for estimation of canagliflozin in dosage form," Research Journal of Pharmaceutical, Biological and Chemical Sciences, vol. 6, no. 5, pp. 1186-1194, 2015.

[13] M. Iqbal, E. Ezzeldin, K. A. Al-Rashood, Y. A. Asiri, and N. L. Rezk, "Rapid determination of canagliflozin in rat plasma by UHPLC-MS/MS using negative ionization mode to avoid adduct-ions formation," Talanta, vol. 132, pp. 29-36, 2015.

[14] M. Iqbal, N. Y. Khalil, A. M. Alanazi, and K. A. Al-Rashood, "A simple and sensitive high performance liquid chromatography assay with a fluorescence detector for determination of canagliflozin in human plasma," Analytical Methods, vol. 7, no. 7, pp. 3028-3035, 2015.

[15] B. M. Ayoub, "Development and validation of simple spectrophotometric and chemometric methods for simultaneous determination of empagliflozin and metformin: Applied to recently approved pharmaceutical formulation," Spectrochimica Acta Part A: Molecular and Biomolecular Spectroscopy, vol. 168, pp. 118-122, 2016.

[16] Chirag and A. Parle, "Development and validation of UV spectrophotometric method for simultaneous estimation of metformin hydrochloride and alogliptin benzoate in bulk drugs and combined dosage forms," Der Pharma Chemica, vol. 6, no. 1, pp. 303-311, 2014.

[17] R. I. El-Bagary, E. F. Elkady, and B. M. Ayoub, "Spectrophotometric methods for the determination of linagliptin in 
binary mixture with metformin hydrochloride and simultaneous determination of linagliptin and metformin hydrochloride using high performance liquid chromatography," International Journal of Biomedical Science, vol. 9, no. 1, pp. 41-47, 2013.

[18] B. M. Ayoub, "UPLC simultaneous determination of empagliflozin, linagliptin and metformin," RSC Advances, vol. 5, no. 116, pp. 95703-95709, 2015.

[19] B. M. Ayoub and O. Abdel-Aziz, "A guide for using experimental design in chromatographic method development: Applied to the analysis of selected anti-diabetic pharmaceutical combinations," Die Pharmazie, vol. 71, no. 12, pp. 683-690, 2016.

[20] R. I. El-Bagary, E. F. Elkady, and B. M. Ayoub, "Liquid chromatographic determination of sitagliptin either alone or in ternary mixture with metformin and sitagliptin degradation product," Talanta, vol. 85, no. 1, pp. 673-680, 2011.

[21] R. I. El-Bagary, E. F. Elkady, and B. M. Ayoub, "Simultaneous determination of sitagliptin and metformin in ternary mixture with sitagliptin acid degradation product," European Journal of Chemistry, vol. 4, no. 4, pp. 360-365, 2013.

[22] P. Sengupta, U. Bhaumik, A. Ghosh et al., "LC-MS-MS development and validation for simultaneous quantitation of metformin, glimepiride and pioglitazone in human plasma and its application to a bioequivalence study," Chromatographia, vol. 69, no. 11-12, pp. 1243-1250, 2009.

[23] R. I. El-Bagary, E. F. Elkady, and B. M. Ayoub, "Liquid chromatographic methods for the determination of vildagliptin in the presence of its synthetic intermediate and the simultaneous determination of pioglitazone hydrochloride and metformin hydrochloride," International Journal of Biomedical Science, vol. 7, no. 3, pp. 201-208, 2011.

[24] M. Wang and I. R. Miksa, "Multi-component plasma quantitation of anti-hyperglycemic pharmaceutical compounds using liquid chromatography-tandem mass spectrometry," Journal of Chromatography B, vol. 856, no. 1-2, pp. 318-327, 2007.

[25] S. Mowaka and B. M. Ayoub, "Comparative study between UHPLC-UV and UPLC-MS/MS methods for determination of alogliptin and metformin in their pharmaceutical combination," Die Pharmazie, vol. 72, no. 2, pp. 67-72, 2017.

[26] S. Mowaka, E. F. Elkady, M. M. Elmazar, and B. M. Ayoub, "Enhanced LC-MS/MS determination of alogliptin and metformin in plasma: Application to a pharmacokinetic study," Microchemical Journal, vol. 130, pp. 360-365, 2017.

[27] S. Mowaka and D. Mohamed, "Novel contribution to the simultaneous analysis of certain hypoglycemic drugs in the presence of their impurities and degradation products utilizing UPLCMS/MS," RSC Advances, vol. 5, no. 74, pp. 60467-60481, 2015.

[28] A. Rasheed and O. Ahmed, Method Development and Validation Study Using UPLC, LAP Lambert Academic Publishing, 2015.

[29] “ICH, Q2 (R1) Validation of analytical procedures," in Proceedings of the International Conference on Harmonization, Geneva, Switzerland, 2005. 

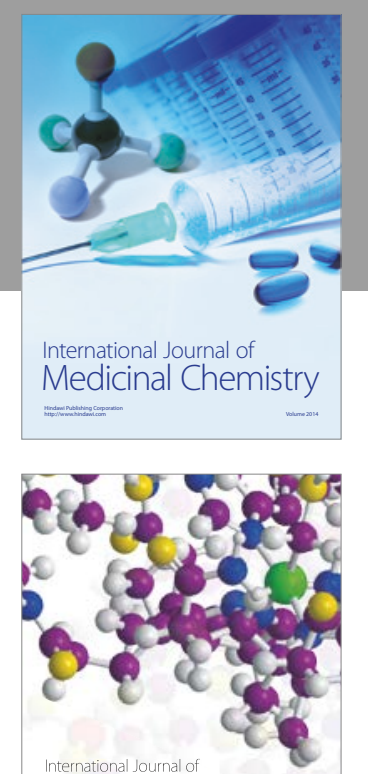

Carbohydrate Chemistry

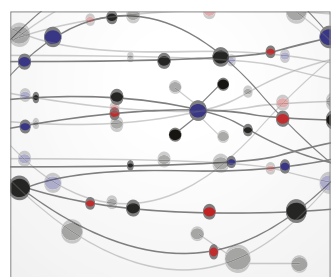

The Scientific World Journal
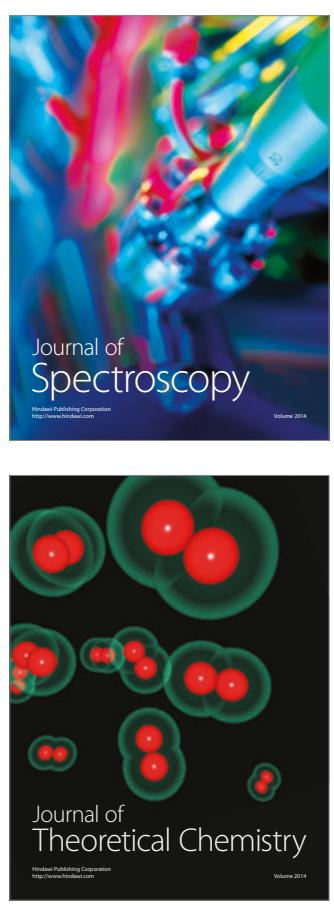
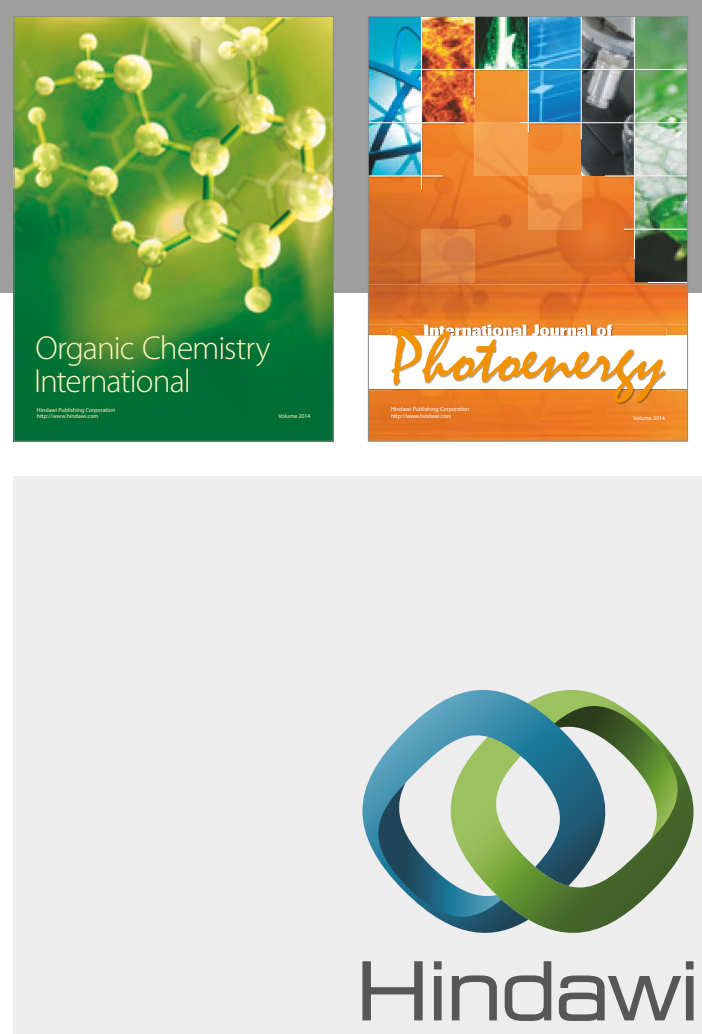

Submit your manuscripts at

https://www.hindawi.com

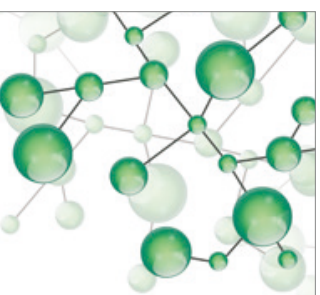

International Journal of

Inorganic Chemistry

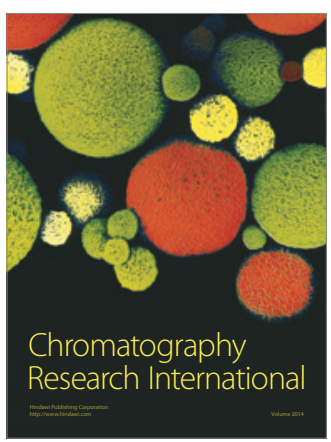

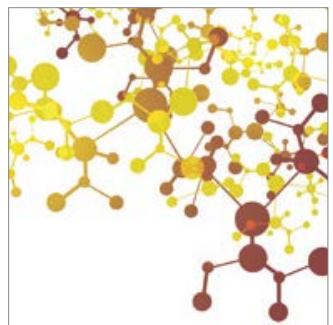

Applied Chemistry
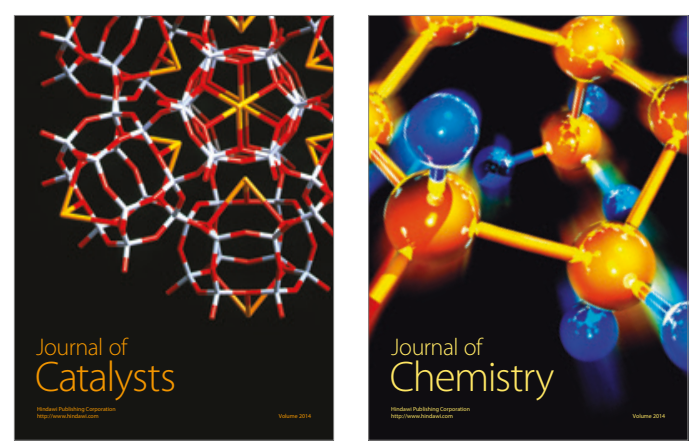
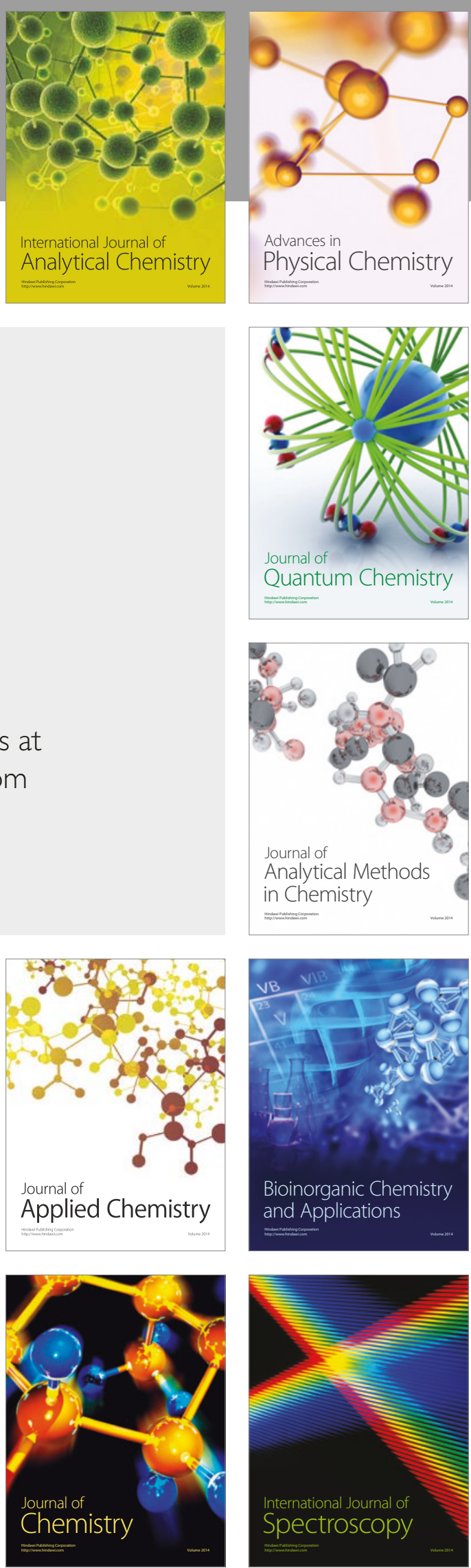